\title{
Inspiratory muscle training as a tool for the management of patients with COPD
}

\section{To the Editors:}

We have been compelled to write to you in response to the editorial by Polkey and Moxham [1] published in the European Respiratory Journal. In their editorial, the authors argue that there is still insufficient evidence to justify the use of inspiratory muscle training (IMT) in patients with chronic obstructive pulmonary disease (COPD). In contrast, we believe that there is a growing evidence base that favours the use of IMT in the overall management of patients with COPD.

POLKEY and MOXHAM [1] argue that studies of IMT should assess efficacy based upon "functionally worthwhile" outcomes. This is a good point, but it appears to be contradicted in their closing paragraph, when they refer specifically to the work of one of us [2]. A 50-60 m improvement in walking performance is dismissed on the basis that it was not accompanied by an improvement in inspiratory muscle function measured using a nonvolitional test of diaphragm function $(P \mathrm{di}, \mathrm{tw})$. We are bound to ask which is the most "functionally worthwhile" outcome: an improvement in walking distance or an improvement in the performance of one, albeit major, inspiratory muscle?

What is most surprising is the authors' enthusiasm for a test $(P \mathrm{di}, \mathrm{tw})$ that they themselves have shown to be so unreliable and that two of us have had cause to criticise it in the past [3]. Data from the authors' own group have shown that the within-subject, between-day reliability of $P$ di,tw is extremely poor, requiring 234 subjects to detect a $10 \%$ effect with 0.8 power, at an alpha level of 0.05 [3]. We think that most people would agree that this technique is too unreliable to be useful in any study with a repeated measures design. Furthermore, the functional relevance of $P$ di,tw is also very questionable, since it completely disregards the contribution made by intercostals and other inspiratory accessory muscles. Here again, the authors' own group have made some relevant offerings. First, KYROUSSIS et al. [4] observed a predominance of ribcage contribution to breathing (over diaphragm) during walking, to the point of intolerable dyspnoea in patients with COPD. The implications of this pattern of recruitment are illustrated by the findings of KYROUSSIS et al. [5] who demonstrated that, after exhaustive exercise in patients with COPD, there was a slowing of the maximum rate of relaxation of the oesophageal pressure response to a submaximal sniff. In the absence of any evidence of diaphragm fatigue, which the authors insist does not occur, one interpretation of this finding is that exercise precipitated inspiratory accessory muscle fatigue. Furthermore, when PoLKEY et al. [6] unloaded the inspiratory muscles of COPD patients during exercise (using mechanical ventilation), they noted an attenuation of the slowing of the maximum relaxation rate of oesophageal pressure. One interpretation of this observation is that the inspiratory accessory muscles may be a site of exercise limitation in patients with COPD. Since this and other evidence points to an important role for inspiratory accessory muscles in exercise ventilation in patients with COPD, we argue that $P$ di,tw lacks the all-important relevance that POLKEY and MOXнам [1] are so keen to see others address in their research. The efficacy of IMT in inducing ribcage muscle remodelling is addressed unequivocally in the landmark study by RAMIREZ-SARMIENTO et al. [7], who observed structural adaptations in external intercostal muscles following IMT in patients with COPD; surely this is a "gold standard" outcome for a group of muscles that are functionally relevant?

POLKey and MOXHAM [1] appear to have selectively and incorrectly reported the findings of the LOTTERS et al. [8] meta-analysis on IMT. First, LOTTERS et al. [8] report a significant influence of IMT upon maximum inspiratory mouth pressure $(P \mathrm{I}, \max )$. Furthermore, a significant effect was noted for dyspnoea, which is a "functionally worthwhile" outcome. Whilst LOTTERS et al. [8] did report a statistically nonsignificant effect of IMT upon walking ability (6- or 12min walking distance), the $p$-value was reasonable $(\mathrm{p}<0.11)$ and the authors drew attention to the fact that there was a tendency for IMT to have a positive influence upon walking distance.

Finally, we are mystified by the insistence of POLKEY and Mохнам [1] that voluntarily evoked forces such as $P$ I,max tell us nothing more than that the subjects "get better at doing the test". Surely learning to activate the muscle that you already have more effectively is just as valuable as growing new muscle? The end result is the same in both instances, i.e. patients can generate higher inspiratory pressures, they are less breathless and can walk further in response to specific IMT.

We are at a loss to comprehend the vehemence of the authors' opposition to inspiratory muscle training; after all, this is a low-cost intervention with no side-effects and a growing evidence base. Viewed in this light, their opposition seems irrational. As scientists, we have a duty to be objective, whilst at the same time being open to new ideas. As Sir William Bragg put it, "The important thing in science is not so much to obtain new facts as to discover new ways of thinking about them."

\author{
A.K. McConnell*, P. Weiner ${ }^{\#}$, L.M. Romer \\ *Dept of Sport Sciences, Brunel University, London, UK. \\ ${ }^{\#}$ Dept of Medicine A, Hillel Yaffe Medical Centre, Hadera, \\ Israel. 'John Rankin Laboratory of Pulmonary Medicine, \\ Dept of Population Health Sciences, University of Wisconsin, \\ WI, USA.
}

A.K. McConnell declares a beneficial interest in the POWERbreathe $\mathbb{R}$ inspiratory muscle trainer

\section{References}

1. Polkey MI, Moxham J. Improvement in volitional tests of muscle function alone may not be adequate evidence that inspiratory muscle training is effective. Eur Respir J 2004; 23 : 5-6.

2. Weiner $\mathrm{P}$, Magadle $\mathrm{R}$, Beckerman $\mathrm{M}$, Weiner $\mathrm{M}$, 
Berar-Yanay N. Maintenance of inspiratory muscle training in COPD patients: one year follow-up. Eur Respir J 2004; 23 : 61-65.

3. McConnell AK, Romer LM, Volianitis S, Donovan KJ. Re: Evaluation of an inspiratory muscle trainer in healthy humans. Respir Med 2002; 96: 129-133.

4. Kyroussis D, Polkey MI, Hamnegard CH, Mills GH, Green M, Moxham J. Respiratory muscle activity in patients with COPD walking to exhaustion with and without pressure support. Eur Respir J 2000; 15: 649-655.

5. Kyroussis D, Johnson LC, Hamnegard CH, Polkey MI, Moxham J. Inspiratory muscle maximum relaxation rate measured from submaximal sniff nasal pressure in patients with severe COPD. Thorax 2002; 57: 254-257.

6. Polkey MI, Kyroussis D, Mills GH, et al. Inspiratory pressure support reduces slowing of inspiratory muscle relaxation rate during exhaustive treadmill walking in severe COPD. Am J Respir Crit Care Med 1996; 154: $1146-1150$.

7. Ramirez-Sarmiento A, Orozco-Levi M, Guell R, et al. Inspiratory muscle training in patients with chronic obstructive pulmonary disease: structural adaptation and physiologic outcomes. Am J Respir Crit Care Med 2002; 166: 14911497.

8. Lotters F, van Tol B, Kwakkel G, Gosselink R. Effects of controlled inspiratory muscle training in patients with COPD: a meta-analysis. Eur Respir J 2002; 20: 570-576.

\section{From the authors:}

We would like to thank A. McConnell and colleagues for their interest in our editorial; such pieces are intended to be thought provoking and it seems that we have achieved this goal. We should initially like to observe that one of us (M.I. Polkey), as associate editor, handled and supported the publication of P. Weiner's paper. We do not think this is evidence of "vehement opposition" to inspiratory muscle training. Nevertheless, even if, as A. McConnell and colleagues argue, the therapy is of unequivocal benefit, this, in our view, makes understanding the basic mechanisms of even greater importance. In fact, some scepticism with regard to inspiratory muscle training is supported by a recent placebo-controlled trial of inspiratory muscle training, which concluded that "specific respiratory muscle training in highly fit competitive subjects may influence endurance exercise performance at most to a very limited extent" [1].

The relative contribution of diaphragm and ribcage muscle to exercise limitation remains a subject of great academic interest. We certainly agree that it is possible to achieve significant levels of exercise using the rib cage muscles alone, as we showed recently in patients with bilateral diaphragm paralysis [2]. This, of course, does not support the reverse: that it is possible to train the rib cage muscles in isolation. Therefore, we believe that a worthwhile training programme should increase the strength and endurance of the diaphragm, as well as that of the extradiaphragmatic inspiratory muscles. We do believe that mechanisms of action are relevant, and A. McConnell and colleagues may be interested in some recently analysed data from our study of the Powerbreathe ${ }^{\mathrm{TM}}$ [3], about which we had correspondence at the time. Both the controls and active groups in that study were also submitted to a trial of inspiratory muscle endurance, which we subsequently analysed using the protocol of HART et al. [4] described in the European Respiratory Journal in 2002. In the group allocated to active intervention, five of six subjects increased their endurance time, as did five of six controls

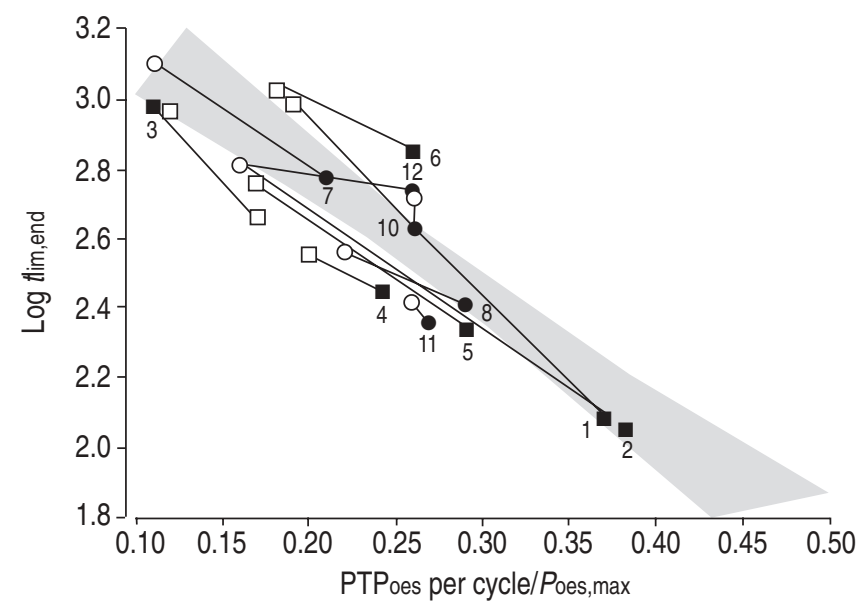

Fig. 1.-Testing respiratory muscle endurance. A plot of endurance time (Log $t$ lim,end) against the inspiratory muscle load to capacity ratio (PTPoes per cycle/Poes,max) in six subjects who underwent inspiratory muscle training $(\square$ and $\square$ ) and nine subjects who underwent sham-training ( and $\bigcirc)$ for a period of 6 weeks (numbers correspond to previously published data [3]; data are missing on subject 9 , which was the subject in the control group that reduced endurance time post inspiratory muscle training). The shaded area represents the "normal values" (regression equation with 95\% confidence bands) [4]. Closed symbols represent pre-training or sham-training, whereas open symbols represent post-training or sham-training, with a vertically upward movement representing an increase in endurance time. Although in most subjects there is an increase in endurance time, the data lie close to the shaded area indicating a change in breathing pattern, rather than a true increase in inspiratory muscle endurance; an increase in inspiratory muscle endurance would be observed as a significant movement away from the shaded area.

studied (fig. 1). However, examination of the nomogram shows that this apparent improvement is achieved by alteration of breathing pattern, rather than any genuine increase in the endurance capacity of the muscle. Therefore, we remain of the view that understanding the mechanism is of utmost importance and this was reflected in our editorial.

\section{N. Hart*, J. Moxham ${ }^{\#}$, M.I. Polkey*}

*Royal Brompton Hospital and "King's College Hospital, London, UK.

\section{References}

1. Sonetti DA, Wetter TJ, Pegelow DF, Dempsey JA. Effects of respiratory muscle training versus placebo on endurance exercise performance. Respir Physiol 2001; 127: 185-199.

2. Hart N, Nickol AH, Cramer D, et al. The effect of isolated unilateral and bilateral diaphragm weakness on exercise performance. Am J Respir Crit Care Med 2002; 165 : $1265-1270$.

3. Hart N, Sylvester K, Ward S, Cramer D, Moxham J, Polkey MI. Evaluation of an inspiratory muscle trainer in healthy humans. Respir Med 2001; 95: 526-531.

4. Hart N, Hawkins P, Hamnegard C-H, Green M, Moxham J, Polkey MI. A novel clinical test of respiratory muscle endurance. Eur Respir J 2002; 19: 232-239. 